\title{
Socioeconomic Factors That Contribute to Criminal Behaviors in Louisiana: Policy Implications
}

\author{
Babatunde Ademola Akinbobola \\ Department of Public Policy \\ Nelson Mandela College of Government and Social Sciences \\ Southern University and A \& M College, Baton Rouge, Louisiana
}

\begin{abstract}
This study investigates the socioeconomic factors that contribute to criminal behaviors in Louisiana by focusing on the residents' perceptions. The study used a survey instrument through the help of google doc (internet) to sample 110 residents of Louisiana across the following cities: Lafayette, Baton Rouge, New Orleans, and Lake Charles. The study was purely descriptive in nature. The study found that the following socioeconomic factors influences criminal activities in the state of Louisiana: modern society, high poverty, low education, and race/ethnicity. The majority of the respondents were of the opinion that the modern society and its structure as well as low education attainment, and high poverty rates play significant role in influencing criminal behaviors. The study therefore suggests that policymakers and law enforcement agencies should enforce the free education policy in the state in order increase the number of people attaining high school certificates/education and to some extent college education. The study further suggests that policymakers should also make available financial aid resources that could easily be accessible by students as a way to motivate them to go to school. More jobs and equal opportunities should be given to all citizens irrespective of body color (or race) to minimize income inequality gap, and poverty among the citizens.
\end{abstract}

Keywords: Crime, Education, Modern-Society, Poverty, Criminal-behavior, Socioeconomic, and Policy

DOI: $10.7176 / \mathrm{PPAR} / 11-7-04$

Publication date:August $31^{\text {st }} 2021$

\section{INTRODUCTION:}

According to Rogers (2007), theories of crime have long assumed that increased criminality is an inevitable consequence of economic and social progress. Gordon (1973) also argued in the literature that the long-term criminal activities in the Western society could be attributed to cultural change in Western society, especially the growing sensitization to violence and the development of increased internal and external controls on aggressive behavior. In the 1960s, when criminologists turned their attention to the Third World, this view was accepted by scholars who built on modernization theory, and it was left unchallenged by the dependency theorists who began studying crime a decade later (Rogers, 2007).

Very importantly, it has been further observed in the literature that the historical studies of crime have now undermined this assumption; in many nations' industrialization, urbanization and rapid social change have been accompanied by declines in crime. As a result, several studies including Rogers (2007), Gordon (1978) and many others have suggested in the literature that long - term trends of crime and criminal law are needed before a necessarily complex theory of crime can be advanced to replace the refuted theories.

In the literature, it was observed that there are two major types of crime that have been investigated over the years, and they are: (a) personal-related crime (Simon, 2010, p.246), and (b) property-related crime (Simon, 2010, p.246). According to Simon (2010), personal-related crimes involved the physical assault or threat of assault on another person's physical being or psyche or crime against oneself with the intent to cause harm. Very importantly, some specific types of personal-related crimes include but not limited to: murder, assault, drug use or dealing, and domestic violence. On the other hand, property-related crimes argued by Simon (2010) involve the taking, damaging, or destroying of property belonging to another individual or individuals. Some emblematic examples of property-related crimes include but not limited to the following: burglary, forgery, vandalism, and arson. Even though causes of crime are really theories about criminal behaviors, but Simon (2010) postulated and challenges scholars to investigate crime by examining the following the concepts: (a) what it is, (b) why it occurs, and (c) what can be done to prevent crime.

Louisiana crime statistics indicate a total downward trend in crime based on data from 20 years when violent crime was decreasing and property crime was decreasing. Based on this report, the crime rate in Louisiana for 2021 is expected to be lower than in 2019 when the state violent crime rate was higher than the national violent crime rate average by $44.78 \%$ and the state property crime rate was higher than the national property crime rate average by $49.86 \%$ (see Figure 1 for more details). 


\section{Figure 1}

Louisiana Index Crime Versus National Index Crime

2019 Property Crime Comparison

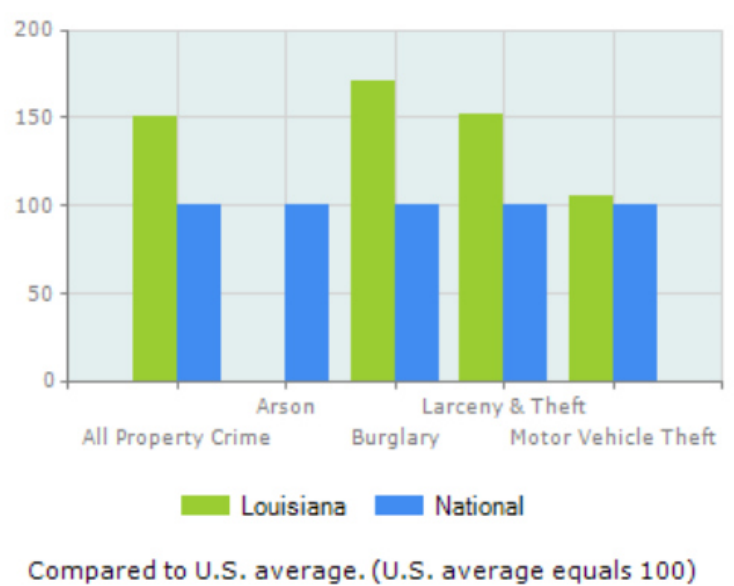

2019 Violent Crime Comparison

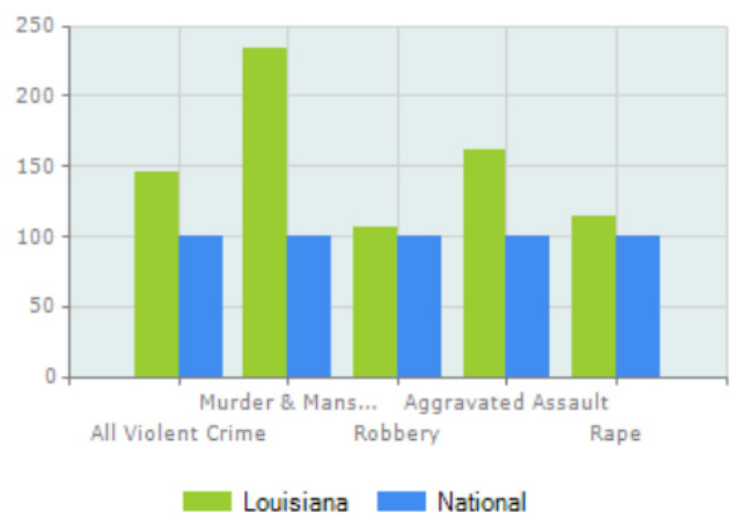

Compared to U.S. average. (U.S. average equals 100)

Source: (CityRating.com, 2021)

Meanwhile, the theories of crime often emerge from studies of genetics, sociology, and psychology (Lyle, 2019). Notwithstanding to long-term discussion of historical trends of crime in the literature, it has been also observed in the literature from a theoretical standpoint that several socioeconomic factors do influence individuals criminal behaviors. Among several of the socioeconomic factors that is considered in this study for the purposes of investigation include: (a) modern society, (b) poverty, (c) education, and (d) race/ethnicity (Simon, 2010, p.246). This study is designed to investigate the extent to which the following factors influence criminal activities or behaviors in Louisiana.

\section{Brief Definitions of the Study Variables}

Modern Society: According to Simon (2010), a sociologist Emile Durkheim argued that modern society and its structure plays a significant role in creating criminal behavior. Meanwhile, society defines illegal behavior; individuals find it difficult to avoid committing a "criminal act" (Simon, 2010, p.250). When society is industrialized it is considered to be modern society or it can be defined as people living together in the current time. An example of modern society is the current political, sociological, scientific and artistic climate. Poverty: Poverty is a possible motivator for certain property crimes, whereas the culture of poverty is an explanation for violent crimes. Poverty is defined in this paper as the state of not having enough material possessions or income for a person's basic needs (Merriam-Webster, 2013). Education: Number of years of having a formal education. Crime theories argue that individuals with lower levels of education have a higher probability of committing criminal acts. The choice to reject formal education may be a "first step" in the development of antisocial attitudes, juvenile delinquency, or deviancy. Education is a powerful driver of development and one of the strongest instruments for reducing poverty and improving health, gender equality, peace, and stability. Race or Ethnicity: Theorists have long discussed subgroup characteristics in relation to general socioeconomic conditions and, more controversially, a subculture's tendency to use violence as an acceptable method of solving disputes or pursuing personal goals. According to Merriam-Webster, race is defined as any one of the groups that humans are often divided into based on physical traits regarded as common among people of shared ancestry; also, the fact of dividing people, or of people being divided, into such groups: categorization by race.

\section{METHODOLOGY}

This study adopts a descriptive research design to examine the socioeconomic factors that influences criminal behaviors in the State of Louisiana. Two data sources were used in this study. A secondary data was retrieved from the CityRating.com (2008) and Crime in Louisiana datasets (2021). Additionally, the study used a survey instrument through the help of google doc (internet) to sample 110 residents of Louisiana across the following cities: Lafayette, Baton Rouge, New Orleans, and Lake Charles to assess the perception of the residents of the selected cities towards the examination of the socioeconomic factors which influences criminal activities or behaviors in Louisiana to inform policy. All the data variables were measured on interval-ratio scale. Tables, bar graphs, and pie-charts were used to analyze the study. Data were processed and analyzed with the help of Microsoft Excel. 


\section{DATA ANALYSIS AND PRESENTATION}

\section{Figure 2}

Louisiana Index Crime

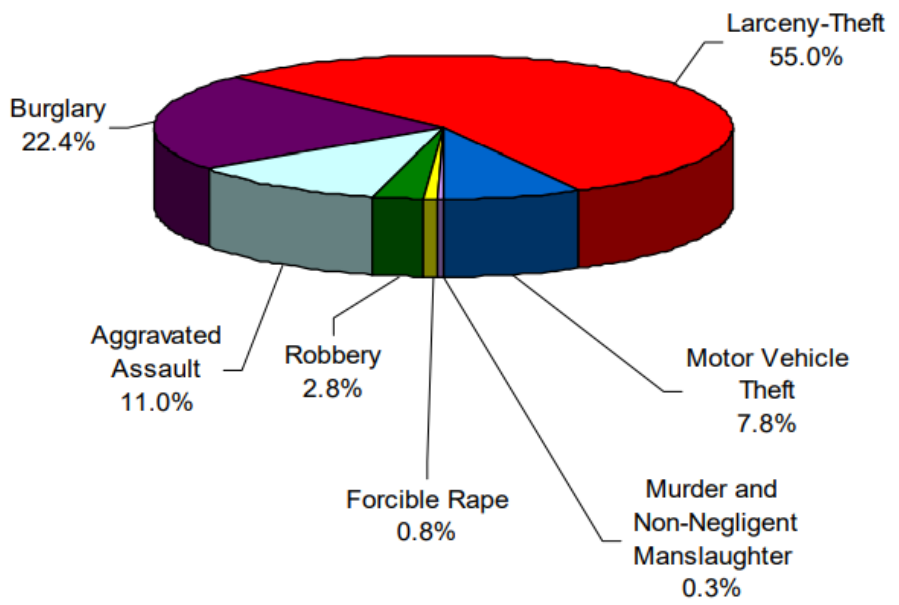

Source: (Crime in Louisiana, 2008)

Figure 2 discuss Louisiana Index Crime retrieved from Crime in Louisiana (2008) datasets. According to the data, about $55 \%$ of the total crime in Louisiana goes to Larceny-Theft, $22.4 \%$ goes to Burglary, $11 \%$ goes to Aggravated Assault, 7.8\% goes to Motor Vehicle Theft, $2.8 \%$ goes to Robbery, $0.8 \%$ goes to Forcible Rape, and $0.3 \%$ of the total crime in Louisiana goes to Murder and Non-Negligent Manslaughter.

\section{Analysis of the Demographic Characteristics of the Study Participants/Respondents}

Figure 3: Gender Category of Respondents

\section{Gender Category of Respondents}

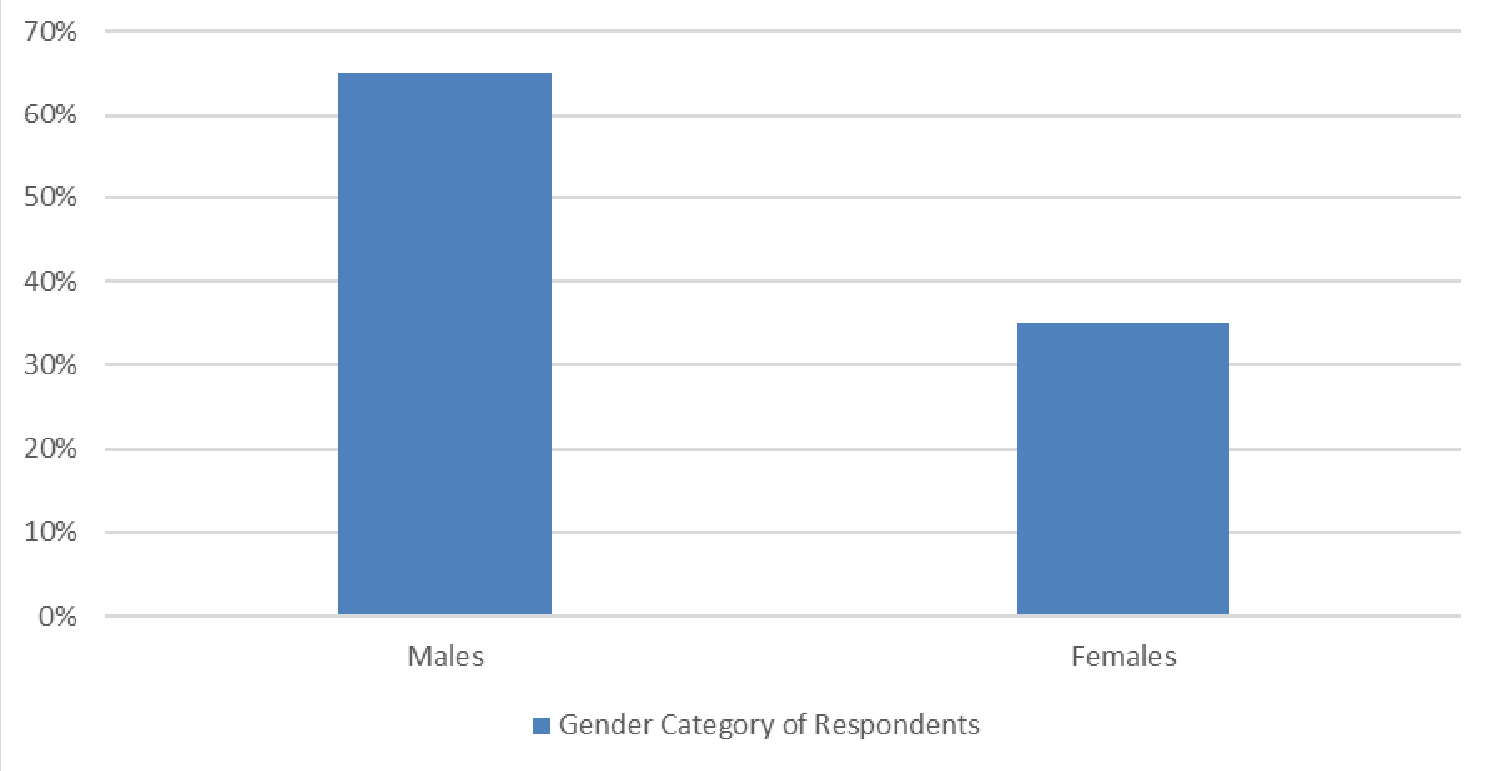

Source of Data: Field Data, 2021

In relation to the field data obtained through survey of about 110 respondents, Figure 3 presents the gender categories of the total respondents. From the data, about $65 \%$ of the respondents from the following cities in Louisiana: Lafayette, Baton Rouge, New Orleans, and Lake Charles were males, while 35\% were females (see Figure 3 for more details). 
Figure 4 also discusses the employment status of the study participants. The data reveals that about $80 \%$ of the respondents both males and females were employed, that is, they are actively engaged in the labor force participation, while $20 \%$ of the respondents were unemployed.

Figure 4: Employment Status of Respondents

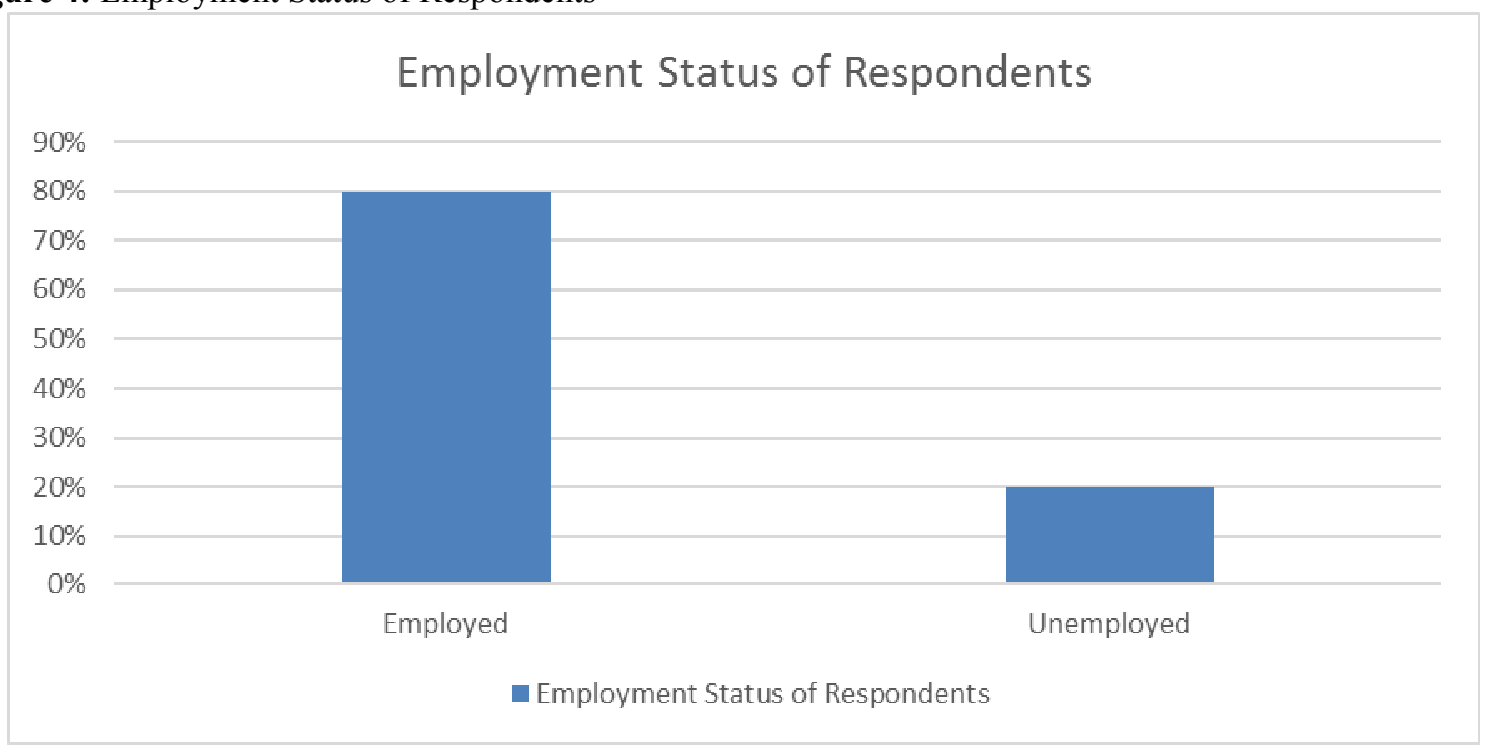

Source of Data: Field Data, 2021

Figure 5 also presents the marital status of the study participants for both males and females. The data reveals that about $50 \%$ of the respondents for both males and females were married, $25 \%$ of the respondents were experiencing divorce, $15 \%$ were separated, and $10 \%$ of the respondents were single.

Figure 5: Marital Status of Respondents

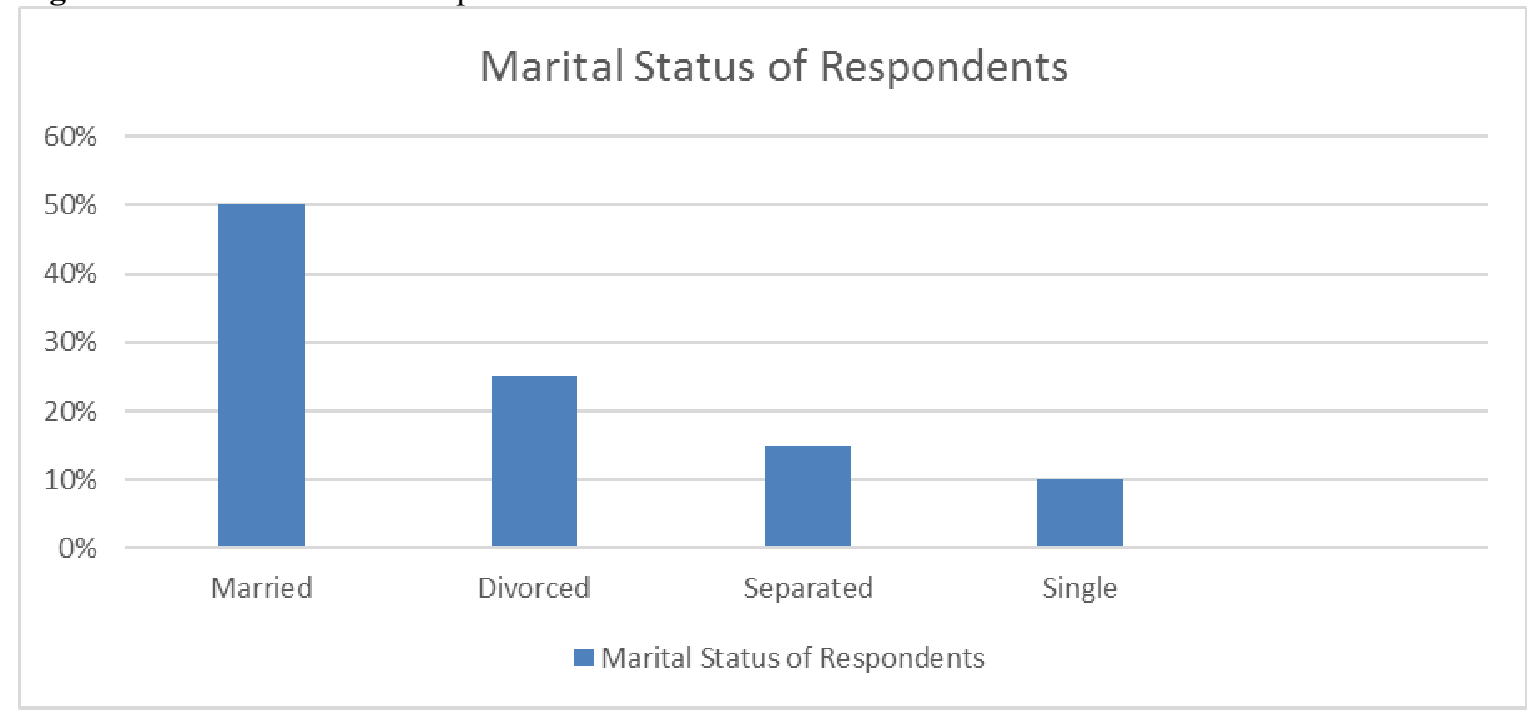

Source of Data: Field Data, 2021 


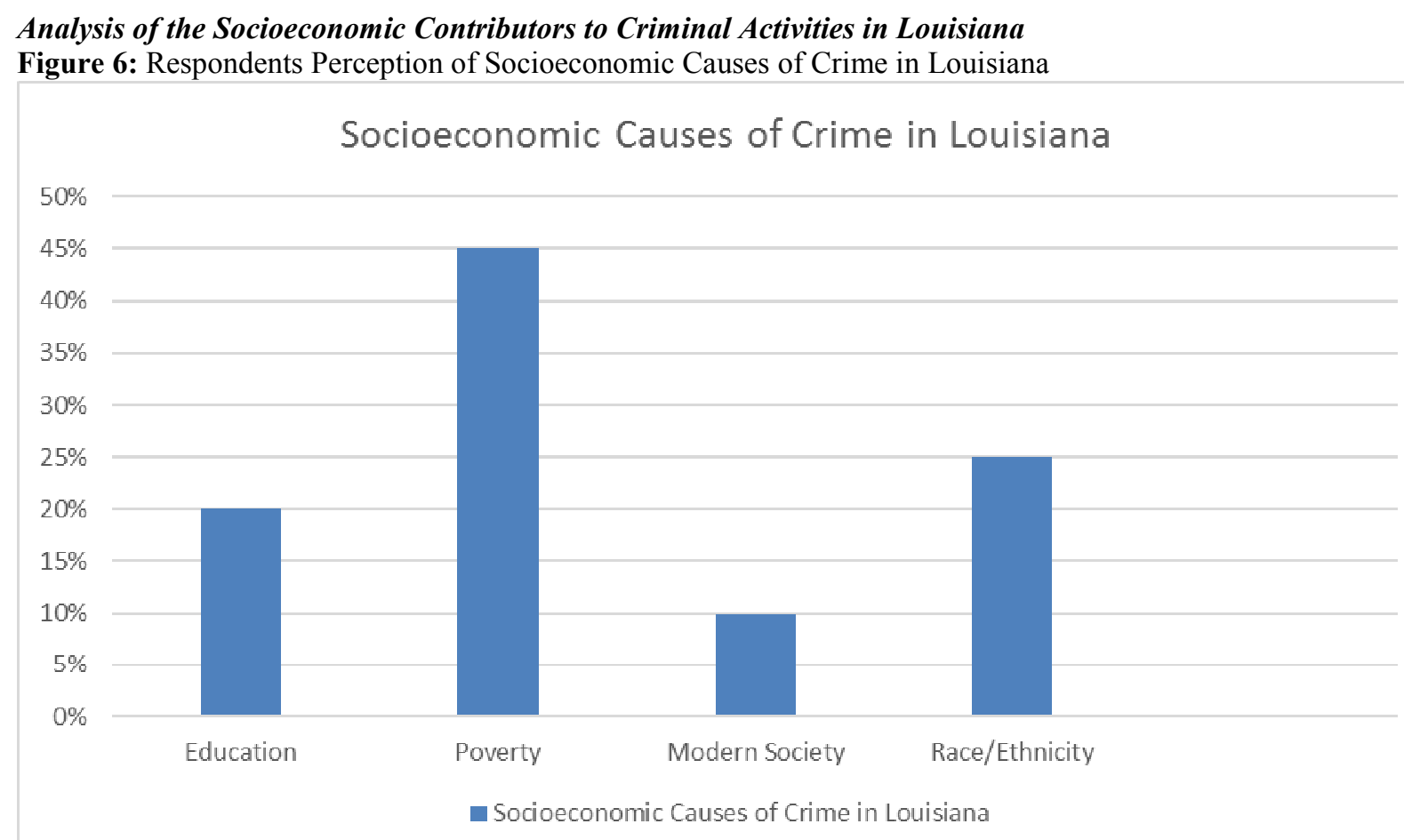

Source of Data: Field Data, 2021

Figure 6 discuss the perception of the respondents in relation to some of the perceived socioeconomic factors that influences crime in Louisiana. According to the data, about of $45 \%$ of the total crime in Louisiana is being influenced by hardship or poverty, $25 \%$ of the total crime is being influenced by ethnic background or race, $20 \%$ by low education, and $10 \%$ of the total crime in Louisiana is being influenced by modern society.

Figure 7: The Degree to Which Modern Society Influences Criminal Activities in Louisiana

\section{To What Extent Do You Agree That Modern Society Influences \\ Criminal Activities in Louisiana}

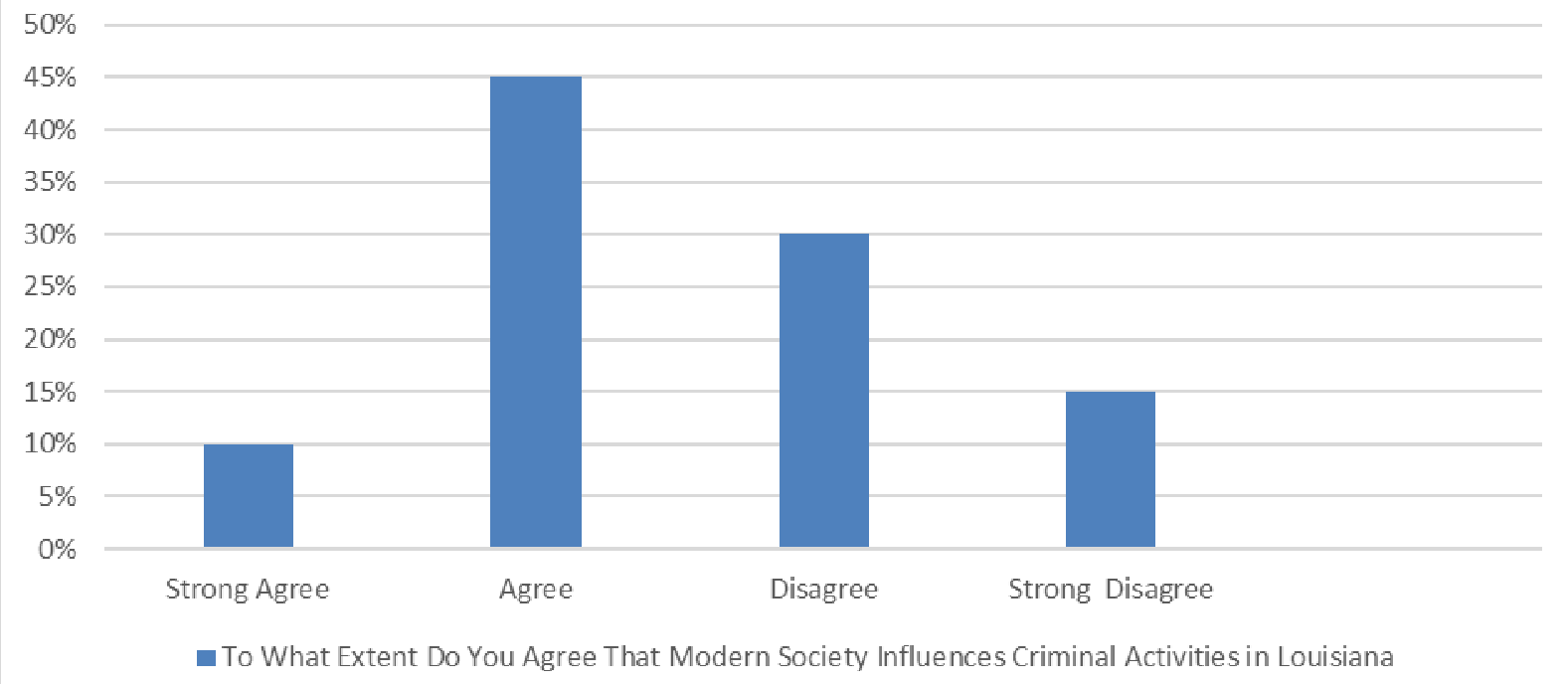

Source of Data: Field Data, 2021

Figure 7 illustrates the perception of the degree to which modern society as one of the perceived socioeconomic factors influences criminal behaviors and activities in Louisiana. According to the data, about $45 \%$ of the total respondents agree to the notion that modern society as one of the perceived socioeconomic factors do influence criminal behaviors and activities in Louisiana, 10\% strongly agree, while 30\% of the total respondents disagree to the notion that modern society as one of the perceived socioeconomic factors do influence criminal behaviors and activities in Louisiana, and 15\% strongly disagree. This implies that about 55\% 
(majority) of the total respondents were of the opinion that modern society as one of the perceived socioeconomic factors do influence criminal behaviors and activities in Louisiana.

Figure 8: The Degree to Which Low Education Attainment Influences Criminal Activities in Louisiana

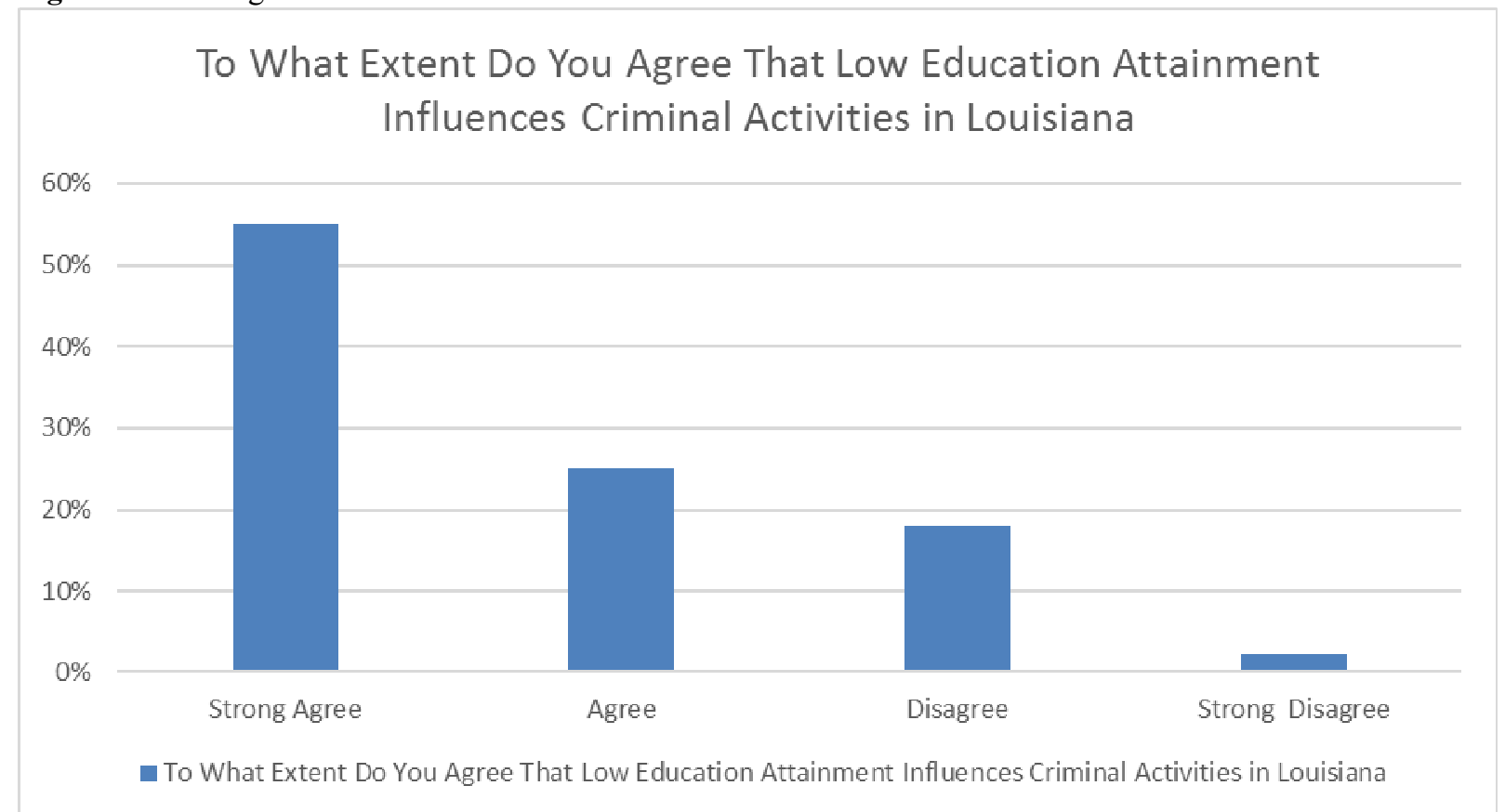

Source of Data: Field Data, 2021

Figure 8 discusses the perception of the degree to which low education attainment as one of the perceived socioeconomic factors influence criminal behaviors and activities in Louisiana. According to the data, about $55 \%$ of the total respondents strongly agree to the notion that low education attainment as one of the perceived socioeconomic factors do influence criminal behaviors and activities in Louisiana, 25\% agree to the notion, while $18 \%$ of the total respondents disagree to the notion that low education attainment as one of the perceived socioeconomic factors do influence criminal behaviors and activities in Louisiana, and $2 \%$ strongly disagree. This implies that about $80 \%$ (majority) of the total respondents were of the opinion that low education attainment as one of the perceived socioeconomic factors do influence criminal behaviors and activities in Louisiana.

Figure 9: The Degree to Which Poverty (or Hardship) Influences Criminal Activities in Louisiana

\section{To What Extent Do You Agree That Poverty

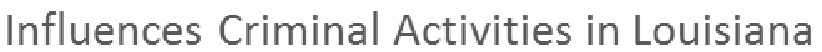

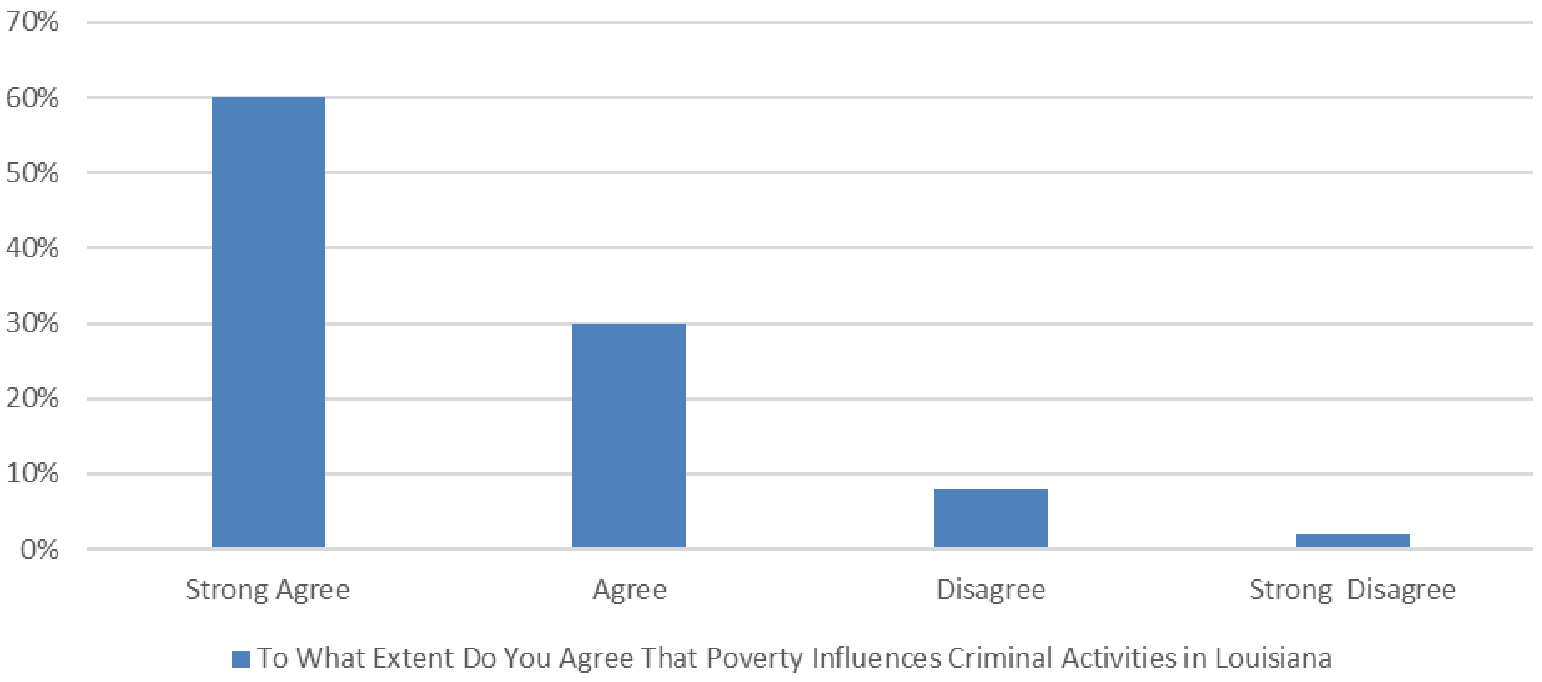

Source of Data: Field Data, 2021

Figure 9 illustrates the perception of the degree to which poverty or hardships as one of the perceived 
socioeconomic factors influence criminal behaviors and activities in Louisiana. According to the data, about $60 \%$ of the total respondents strongly agree to the notion that poverty or hardships as one of the perceived socioeconomic factors do influence criminal behaviors and activities in Louisiana, 30\% agree to the notion, while $8 \%$ of the total respondents disagree to the notion that poverty or hardships as one of the perceived socioeconomic factors do influence criminal behaviors and activities in Louisiana, and $2 \%$ strongly disagree. This implies that about $90 \%$ (majority) of the total respondents were of the opinion that poverty or hardships as one of the perceived socioeconomic factors do influence criminal behaviors and activities in Louisiana.

Figure 10: The Degree to Race/Ethnic Background Influences Criminal Activities in Louisiana

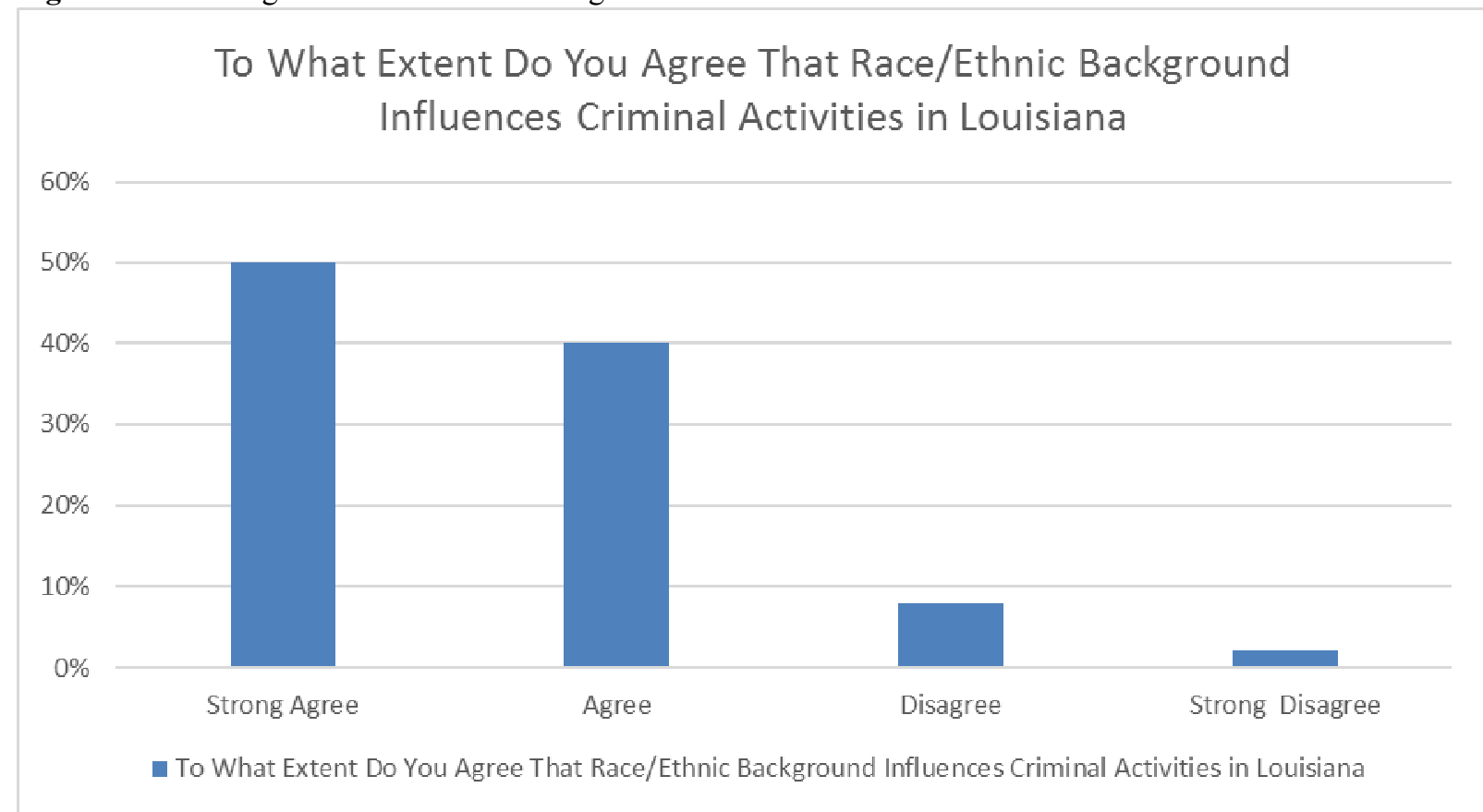

Source of Data: Field Data, 2021

Figure 10 illustrates the perception of the degree to which race or ethnicity as one of the perceived socioeconomic factors influences criminal behaviors and activities in Louisiana. The data revealed that about $50 \%$ of the total respondents strongly agree to the notion that race or ethnicity as one of the perceived socioeconomic factors do influence criminal behaviors and activities in Louisiana, 40\% agree to the notion, while $8 \%$ of the total respondents disagree to the notion that race or ethnicity as one of the perceived socioeconomic factors do influence criminal behaviors and activities in Louisiana, and $2 \%$ strongly disagree. This implies that about $90 \%$ (majority) of the total respondents were of the opinion that race or ethnicity as one of the perceived socioeconomic factors do influences criminal behaviors and activities in Louisiana.

\section{CONCLUSION AND POLICY IMPLICATIONS}

Towards this end, the study found that the following socioeconomic factors: modern society, high poverty, low education, and race/ethnicity influence criminal activities in the state of Louisiana. The majority of the respondents were of the opinion that the modern society and its structure as well as low education attainment, and high poverty or hardships play significant role in creating criminal behavior. Based on the findings, and in an attempt to minimize crime by tackling some of the socioeconomic factors that influence crime in Louisiana, the study therefore suggests that policymakers and law enforcement agencies should enforce the free education policy in the state in order increase the number of people attaining high school certificates/education and to some extent college education. The study further suggests that policymakers should also make available financial aid resources that could easily be accessible by students as a way to motivate them to go to school. Above all, more jobs and equal opportunities should be given to all citizens irrespective of body color and race to minimize income inequality gap, and poverty (or hardship). By implementing all these measures will go a long way to minimize crime in the state of Louisiana that is being caused by socioeconomic factors.

\section{REFERENCES}

Archer, Dane and Gartner, Rosemary. (1984). Violence and Crime in Cross - National Perspective, New Haven, CT: Yale University Press.

Bandarage, A. (1983). Colonialism in Sri Lanka: The Political Economy of the Kandyan Highlands, 1833-1886, Berlin: Mouton. 
Barlow, H. D. (1984). Introduction to Criminology, Boston, MA: Little Brown.

Brana - Shute, R. and Brana - Shute, G. (1980). Crime and Punishment in the Caribbean, Gainesville, FL: Center for Latin American Studies, University of Florida.

Cameron, Iain A. (1981). Crime and Repression in the Auvergne and the Guyenne, 1720-1790, Cambridge: Cambridge University Press. [Google Scholar]

Clinard, M. B. and Abbott, D. J. (1973). Crime in Developing Countries: A Comparative Perspective, New York: John Wiley. [Google Scholar]

Gatrell, V.A.C. (1980). "The Decline of Theft and Violence in Victorian and Edwardian England". In Crime and the Law: The Social History of Crime in Western Europe since 1500, Edited by: Gatrell, V.A.C., Lenman, B. and Parker, G. London: Europa. [Google Scholar]

George, B. J. (1982). Criminal Justice in Asia: The Quest for an Integrated Approach, Tokyo: United Nations Asia and Far East Institute for the Prevention of Crime and Treatment of Offenders. [Google Scholar]

Gordon, D. M. (1973). 'Capitalism, Class, and Crime in America'. Crime and Delinquency, 19(2): $163-86$. [Crossref], [Web of Science $\left.{ }^{\circledR}\right]$, [Google Scholar]

Lyle, P. (2019). Sociological Theories of Crime: Control Theory Review. (8) (PDF) Sociological Theories of Crime: Control Theory Review | Dr Perry Lyle, PhD - Academia.edu

Rogers, J.D. (2007). Theories of crime and development: an historical perspective. The Journal of Development Studies. https://doi.org/10.1080/00220388908422114

Simon, C. A. (2010). Public Policy: preference and Outcomes, $2^{\text {nd }}$ edition. Pearson Education, Inc. 